\title{
Preserving the rectus muscle during laparoscopically harvesting an omental flap
}

\author{
Jan J. van Wingerden • Eric R. Totte
}

Published online: 29 December 2009

(c) The Author(s) 2009. This article is published with open access at Springerlink.com

To the Editor,

Due to the technical advances in laparoscopic surgery, we are indeed able to welcome a new dawn for the versatile use of the omentum in reconstructive surgery. The large experience of and excellent documentation by Zaha and Inamine [1] in laparoscopically harvesting the omental flap, pedicled or free, in 96 patients should not go unnoticed. The description of their dissection technique is so lucid that it could easily be adopted by other endoscopic surgeons, regardless of the indication. We would like to draw your attention to a small, but to our mind significant, technical point.

The laparoscopically harvested omental flap has many uses but is particularly suitable for selected cases that require reconstructive breast surgery and effective for the treatment of mediastinitis or reconstruction of the sternum after deep sternal wound infection (DSWI) or sternal osteomyelitis. Both conditions, albeit a distant second or third choice, also can be managed by transposition of a pedicled rectus abdominis, either as a muscle or as a musculocutaneous (TRAM or VRAM) flap. Direct injury to the rectus muscle or the superior epigastric vessels (SEV), resulting in a muscle hematoma and subsequent fibrosis or interruption of flow, however small the risk, should be avoided. Apart from a few anecdotal reports and a small case series $(n=5)$ [2] on the successful transposition of

J. J. van Wingerden $(\bowtie)$

Department of Plastic, Reconstructive and Hand Surgery,

Academic Medical Center, University of Amsterdam,

P.O. Box 22660, 1100 DD Amsterdam, The Netherlands

e-mail: j.j.vanwingerden@amc.uva.nl

E. R. Totte

Leeuwarden Institute for Minimal Invasive Surgery (LIMIS),

Medical Center Leeuwarden, Leeuwarden, The Netherlands the pedicled rectus muscle to the chest after ligation of the ipsilateral inferior mammary artery (IMA), there have been none where the SEV had been transected. Furthermore, the delay required for the collateral circulation to develop may be too long for some patients to wait. Zaha and Inamine [1] state that the port in the right upper quadrant was inserted "at the level of a wedge of the rectus muscle...." We would rather recommend, as we did previously [3], that the port should be sited lateral to the rectus muscle wherever possible.

Keeping a lifeboat intact should, also in reconstructive surgery, always be a priority; one way is to avoid an unplanned encounter with a vessel!

Disclosures Drs. Van Wingerden and Totte have no conflicts of interest or financial ties to disclose.

Open Access This article is distributed under the terms of the Creative Commons Attribution Noncommercial License which permits any noncommercial use, distribution, and reproduction in any medium, provided the original author(s) and source are credited.

\section{References}

1. Zaha H, Inamine S (2009) Laparoscopically harvested omental flap: results for 96 patients. Surg Endosc doi:10.1007/s00464009-0533-0 [4 June 2009]

2. Netscher DT, Eladoumikdachi F, Goodman CM (2001) Rectus abdominis muscle flaps used successfully for median sternotomy wounds after ipsilateral internal mammary artery ligation. Ann Plast Surg 47:223-228

3. van Wingerden JJ, Coret EH, van Nieuwenhoven CA, Totte ER (2009) Laparoscopically harvested omental flap for deep sternal wound infection. Eur J Cardiothorac Surg doi:10.1016/j.ejcts.2009. 06.020 [29 July 2009] 